\title{
Female gender as a determinant of cough threshold to inhaled capsaicin
}

\author{
M. Fujimura*, K. Kasahara**, Y. Kamio+, M. Naruse ${ }^{++}$, T. Hashimoto ${ }^{\dagger}$, T. Matsuda*
}

Female gender as a determinant of cough threshold to inhaled capsaicin. M. Fujimura, K. Kasahara, Y. Kamio, M. Naruse, T. Hashimoto, T. Matsuda. @ERS Journals Ltd 1996. ABSTRACT: Chronic, nonproductive cough and cough associated with the use of angiotensin converting enzyme inhibitors, are more frequently observed in females as compared to males.

To examine the influence of sex, age, height, weight and pulmonary function on airway cough sensitivity, cough threshold to inhaled capsaicin, an index of the airway cough sensitivity, was measured in 160 nonsmoking, nonatopic healthy subjects. Forty young males (aged $24 \pm 2$ yrs) 40 young females (aged 22 \pm 2 yrs) 40 middle-aged males (aged $48 \pm 5 \mathrm{yrs}$ ) and 40 middle-aged females (aged $50 \pm 7 \mathrm{yrs}$ ) were studied. The cough threshold was defined as the lowest concentration of inhaled capsaicin causing five or more coughs.

The cough threshold was 3-5 fold lower in females than in males both in young $(p<0.001)$ and middle-aged $(\mathbf{p}<0.005)$ subjects. Cough threshold was weakly but significantly correlated to height, weight, forced vital capacity (FVC) and forced expiratory volume in one second (FEV1) when all subjects were considered together but not when each group was considered separately. Multiple regression analysis revealed that sex difference was the significant predictive factor for the cough threshold in either age group.

These results confirm that cough sensitivity is heightened in females and suggest that influence of height and pulmonary function on the cough threshold may have resulted from sex difference.

Eur Respir J., 1996, 1624-1626.
*The Third Department of Internal Medicine, and ${ }^{\top}$ Dept of Laboratory Medicine, Kanazawa University School of Medicine, Kanazawa, Japan. **Division of Pulmonary Medicine, and ${ }^{++}$Clinical Laboratory, Kanazawa Citizen's Hospital, Kanazawa, Japan. ${ }^{\text {The }}$ Central Laboratory, Kanazawa University Hospital, Kanazawa, Japan.

Correspondence: M. Fujimura

The Third Department of Internal Medicine Kanazawa University School of Medicine 13-1 Takara-machi

Kanazawa 920

Japan

Keywords: Age, airway cough sensitivity, capsaicin, normal humans, pulmonary functions, sex

Received: June 271995

Accepted after revision May 71996

This study was supported in part by a Grantin-Aid for Scientific Research from the Ministry of Education, Science and Culture (04807055) by the Japanese Government.
Cough is one of the commonest respiratory symptoms. Angiotensin-converting enzyme (ACE) inhibitors cause cough in 5-20\% of patients who receive them, and females are more susceptible than males [1]. In addition, we have shown that chronic persistent nonproductive cough, resistant to bronchodilators, is more frequent in females [2, 3]. Irritant receptors, and possibly C-fibre endings, are generally recognized as cough receptors in the airways $[4,5]$. Capsaicin, a commonly used cough stimulant, is the active ingredient of red pepper and has been presumed to produce cough mainly by stimulating $\mathrm{C}$-fibre endings [6-8], though its action may be indirect [5].

In normal subjects, reproducibility of dose-response curve for capsaicin-induced cough has been well-established, when the challenge is repeated at an interval of more than 15 min [9]. Recently, Midgren et al. [10] have confirmed the reproducibility of sensitivity as well as of dose-response curve for capsaicin-induced cough. We [11] have previously reported that cough sensitivity to a chemostimulant, tartaric acid, which may produce cough by stimulating irritant receptors, is greater in young females than in young males.

The present study was designed to determine whether capsaicin induced cough, which may have a greater dependence on C-fibre afferents, is more sensitive in females than in males and to examine whether the cough sensitivity is influenced by age, height or pulmonary function.

\section{Subjects and methods}

\section{Subjects}

One hundred and sixty healthy, nonsmoking, nonatopic volunteers participated in this study. The groups studied comprised: 40 males (aged $24 \pm 2$ yrs (mean \pm SD)) and 40 females (aged $22 \pm 2$ yrs) as "young adult" subjects; and 40 males (aged $48 \pm 5$ yrs) and 40 females (aged $50 \pm 7$ yrs) as "middle-aged" subjects. None of the subjects had allergic disease or a past or family history of allergic disease. The characteristics of the subjects studied are presented in table 1 . The study was approved by the Ethics Committee of Kanazawa university, and informed consent was obtained from all subjects after the purpose of the test had been explained.

\section{Pulmonary function testing}

Forced vital capacity (FVC) and forced expiratory volume in one second (FEV1) were measured using a dry wedge spirometer (Transfer Test; P.K. Morgan Ltd, UK) before the capsaicin provocation test. Three measurements of spirometry were carried out and the best FVC and FEV1 value of the three was kept for data analysis.

\section{Assessment of cough sensitivity to inhaled capsaicin}

Measurement of cough threshold to inhaled capsaicin was carried out using the method reported previously 
Table 1. - Characteristics of the subjects studied

\begin{tabular}{lccccc}
\hline & \multicolumn{2}{c}{ Young } & & \multicolumn{2}{c}{ Middle-aged } \\
\cline { 2 - 3 } \cline { 6 - 7 } & $\begin{array}{c}\text { Male } \\
(\mathrm{n}=40)\end{array}$ & $\begin{array}{c}\text { Female } \\
(\mathrm{n}=40)\end{array}$ & & $\begin{array}{c}\text { Male } \\
(\mathrm{n}=40)\end{array}$ & $\begin{array}{c}\text { Female } \\
(\mathrm{n}=40)\end{array}$ \\
\hline Age yrs & $24 \pm 2$ & $22 \pm 2$ & & $48 \pm 5$ & $50 \pm 7$ \\
Height cm & $172 \pm 6$ & $159 \pm 5$ & & $167 \pm 5$ & $155 \pm 6$ \\
Weight kg & $67 \pm 9$ & $54 \pm 6$ & & $64 \pm 8$ & $55 \pm 9$ \\
FVC L & $5.02 \pm 0.62$ & $3.41 \pm 0.47$ & & $4.09 \pm 0.59$ & $2.85 \pm 0.49$ \\
FEV1 L & $4.40 \pm 0.08$ & $3.06 \pm 0.44$ & & $3.36 \pm 0.46$ & $2.35 \pm 0.41$ \\
FEV1/FVC \% & $88 \pm 6$ & $90 \pm 5$ & & $83 \pm 5$ & $83 \pm 7$
\end{tabular}

Data are presented as mean \pm SD. FVC: forced vital capacity; FEV1: forced expiratory volume in one second.

$[12,13]$. Capsaicin $(30.5 \mathrm{mg})$ was dissolved in Tween $80(1 \mathrm{~mL})$ and ethanol $(1 \mathrm{~mL})$ and then dissolved in physiological saline $(8 \mathrm{~mL})$ to provide a stock solution of $1 \times 10^{-2} \mathrm{M}$, which was stored at $-20^{\circ} \mathrm{C}$. This solution was diluted with physiological saline to make solutions of $0.49,0.98,1.95,3.9,7.8,15.6,31.2,62.5,125,250,500$ and $1,000 \mu \mathrm{M}$. Each subject inhaled a control solution of physiological saline, followed by progressively increasing concentrations of the capsaicin solution. Solutions were inhaled for $15 \mathrm{~s}$ every $60 \mathrm{~s}$, by tidal mouth-breathing wearing a noseclip from a Bennett Twin nebulizer (3012-60 cc; Puritan-Bennett Co., Carlsbad, CA, USA) operated by compressed air at $5 \mathrm{~L} \cdot \mathrm{min}^{-1}$. Increasing concentrations were inhaled until five or more coughs were elicited. The nebulizer output was $0.21 \mathrm{~mL} \cdot \mathrm{min}^{-1}$. It has been reported that aerodynamic mass median diameter (MMD) of the particle is $3.60 \mu \mathrm{M}$, with a geometric standard deviation of 3.47 [14]. Capsaicin-induced cough number was counted by two medical technicians in the pulmonary function laboratory. Cough threshold was defined as the lowest concentration of capsaicin that elicited five or more coughs.

\section{Data analysis}

Capsaicin cough threshold values were expressed as geometric means with the geometric standard error of the mean (GSEM) expressed as a factor. Geometric mean value for cough threshold was compared between any pair of the four groups using Mann-Whitney's nonparametric analysis. In assessing the correlations of cough threshold to age, height, weight, FVC, FEV1 and FEV1/FVC ratio, Spearman rank correlation analysis was employed. Furthermore, multiple regression analysis was performed to assess contributions of these factors and sex to the cough threshold. A p-value of 0.05 or less was taken as significant.

\section{Results}

A cough threshold was obtained in all subjects. Individual values for the cough threshold are shown in figure 1 . In young adults, the geometric mean value of cough threshold in females was $8.22 \mu \mathrm{M}$ (GSEM 1.25), which was significantly lower than that in males, $(45.0 \mu \mathrm{M}$, GSEM 1.18) $(\mathrm{p}<0.001)$. In middle-aged subjects, the value was also significantly $(\mathrm{p}<0.005)$ lower in females $(10.9 \mu \mathrm{M}$, GSEM 1.32) than in males, $(31.8 \mu \mathrm{M}$, GSEM 1.23). The cough threshold was not significantly different between young and middle-aged subjects of the same sex.

Logarithmic value for the cough threshold did not significantly correlate to age, height, weight, FVC, FEV1

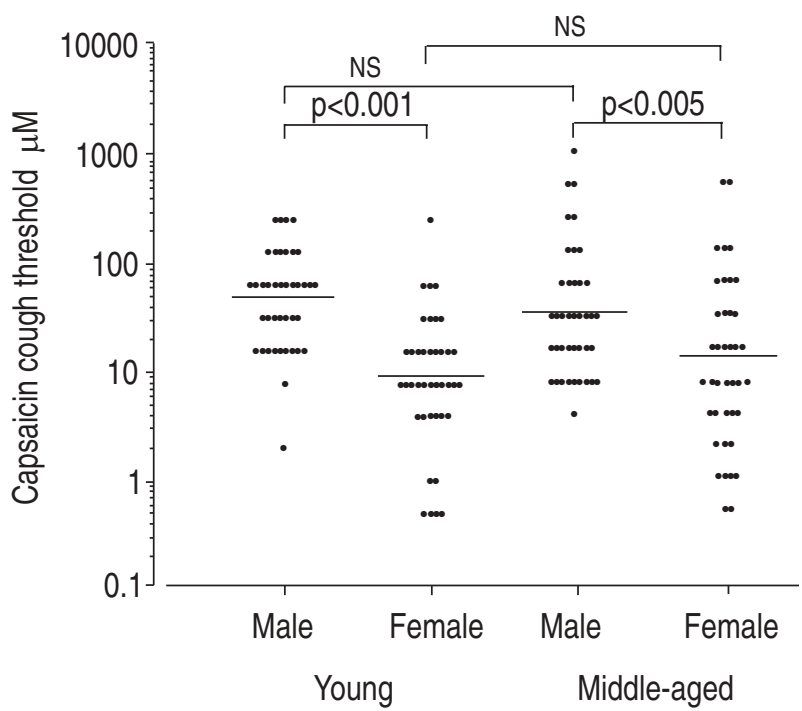

Fig. 1. - Cough threshold to inhaled capsaicin, defined as the lowest concentration of capsaicin eliciting five or more coughs in nonsmoking, nonatopic, healthy subjects. Each horizontal bar shows geometric mean value of capsaicin threshold, defined as the lowest concentration of capsaicin solution causing five or more coughs. NS: nonsignificant.

or FEV1/FVC in each group. When Spearman rank correlation analysis was performed in the whole group of subjects, height $(\mathrm{r}=0.313 ; \mathrm{p}<0.01)$, weight $(\mathrm{r}=0.233$; $\mathrm{p}<0.01)$, FVC $(\mathrm{r}=0.385 ; \mathrm{p}<0.01)$, and FEV1 $(\mathrm{r}=0.352$; $\mathrm{p}<0.01$ ) correlated significantly to logarithmic value of the cough threshold but all of the r-values were very small. Neither age nor FEV1/FVC ratio significantly correlated to the cough threshold. A multiple regression analysis was performed with logarithmic value for capsaicin cough threshold as the dependent variable and sex, age, height, weight, FVC, and FEV1/FVC ratio, as independent variables. This showed significant contribution of sex, but not age, height, weight, FVC or FEV1/FVC ratio, to the capsaicin cough threshold. Namely, the overall adjusted coefficient of multiple regression for prediction of capsaicin cough threshold by these examined variables was $1.187(\mathrm{p}<0.0001)$, and partial regression coefficient for sex was $-0.485(\mathrm{p}<0.01)$.

Among the 40 middle-aged females, 16 were postmenopausal. Capsaicin cough threshold was 16.1 (GSEM 38.0) $\mu \mathrm{M}$ in premenopausal subjects in this group, significantly $(\mathrm{p}<0.05)$ greater than that in postmenopausal subjects $(6.03$ (GSEM 1.58) $\mu \mathrm{M})$. There were no significant differences in age, height, weight, FVC, FEV1 or FEV1/FVC between these two subgroups.

\section{Discussion}

This study showed that capsaicin cough threshold was significantly lower in females than in males both in young and in middle-aged subjects. Cough threshold was weakly but significantly correlated to each of height, weight, FVC and FEV1 in the entire population of subjects, but not in each subject group. Multiple regression analysis revealed that sex difference was the most important predicting factor for the cough threshold, whilst age, height, weight or pulmonary function were not significant factors influencing the cough sensitivity.

It has been postulated that capcaicin, the active ingredient of red pepper, produces cough mainly by stimulating 
C-fibre endings [6-8], but as capsaicin also stimulates some rapidly adapting receptors with myelinated fibres, this view has been questioned $[5,15]$. Inhaled capsaicin probably acts mainly on the larynx, trachea and major bronchi, which are areas of the greatest sensitivity for provocation of cough $[16,17]$. Although the larynx may be the initial site of cough stimulation, the sublaryngeal airways may also contribute to the response, as we have found that patients with a laryngectomy cough when they inhale capsaicin through their tracheostomy tubes. Furthermore, HANSSON et al. [18] have concluded that capsaicin sensitive sensory neurons mediating cough are present in human intrapulmonary airways after noting that concentrations of capsaicin solution causing five coughs were $5.5 \mu \mathrm{M}$ with slow inhalation of a small droplet aerosol (3.2 $\mu \mathrm{M}$ MMD) and $29.5 \mu \mathrm{M}$ with rapid inhalation of a large droplet aerosol (5.2 $\mathrm{\mu M}$ MMD).

Cough reflex testing using capsaicin has been commonly used for studies on the pathophysiology of the cough reflex and the antitussive effects of drugs [10]. In normal subjects, the reproducibility of the dose-response curve for capsaicin-induced cough has been well-established, when the challenge is repeated at an interval of more than $15 \mathrm{~min}$ [9]. In the present study, cough threshold to inhaled capsaicin was measured as an index representing airway cough sensitivity, which was defined as the lowest concentration of capsaicin eliciting five or more coughs $[12,13]$. Reproducibility of the cough threshold has been confirmed by our previous studies [12, 13], when the challenge was repeated at an interval of $30 \mathrm{~min}$ to 2 weeks in normal subjects. Our preliminary study has shown that cough number induced by cough threshold concentration of capsaicin given by the present protocol is not significantly different from that caused by a single $15 \mathrm{~s}$ inhalation of the cough threshold concentration of capsaicin measured on another day in normal subjects.

Although we previously reported that cough sensitivity to inhaled tartaric acid was greater in young females than in young males [11], and the present study has confirmed the sex difference both in young and middle-aged subjects, Choudry and Fuller [19] reported that there was no sex difference in capsaicin-induced cough using a single breath inhalation of increasing concentrations of capsaicin. The apparent contradiction between these two studies may result from difference of inhalation method: $15 \mathrm{~s}$ tidal breathing inhalation in our studies versus single breath inhalation in their study. The sex difference in cough reflexes may explain the greater susceptibility of females to coughing as a side effect of ACE inhibitors [1], and to chronic bronchodilator-resistant nonproductive cough associated with atopy (atopic cough) [2, 3].

If sex difference in cough sensitivity results from female hormones, one might expect it to lessen with the menopause. However, the capsaicin cough sensitivity was slightly greater among the postmenopausal subgroup in this study. This may explain the fact that ACE inhibitors cause cough more frequently in postmenopausal females [1]. The menstrual cycle does not influence the capsaicin cough threshold in young females (unpublished data). In summary, we are not yet able to account for the greater cough sensitivity among females, but it cannot be explained simply in terms of female hormone.

In conclusion, the airway cough reflex in response to inhaled capsaicin, probably mediated directly or indirectly by $\mathrm{C}$-fibre endings, was more sensitive in females than in males. The results extend our previous findings that females have a lower cough threshold to inhaled tartaric acid than males.

\section{References}

1. Gibson GR. Enalapril-induced cough. Arch Intern Med 1989; 149: 2701-2703.

2. Fujimura M, Sakamoto S, Matsuda T. Bronchodilatorresistive cough in atopic patients: bronchial reversibility and hyperresponsiveness. Intern Med 1992; 31: 447-452.

3. Fujimura M, Kamio Y, Hashimoto T, Matsuda T. Cough receptor sensitivity and bronchial responsiveness in patients with only chronic nonproductive cough. in view of effect of bronchodilator therapy. J Asthma 1994; 31: 463-472.

4. Coleridge HM, Coleridge JCG, Ginzel A, Barker DG, Banzett RB, Morrison MA. Stimulation of "irritant receptors" and afferent $\mathrm{C}$ - fibres in the lungs by prostaglandins. Nature 1976; 264: 451-453.

5. Widdicombe JG. Neurophysiology of the cough reflex. Eur Respir J 1995; 8: 1193-1202.

6. Coleridge HM, Coleridge JCG. Impulse activity in afferent vagal C-fibres with endings in the intrapulmonary airways of dogs. Respir Physiol 1977; 29: 125-142.

7. Fuller RW, Jackson DM. Physiology and treatment of cough. Thorax 1990; 45: 425-430.

8. Lundberg JM, Saria A. Capsaicin-induced desensitization of airway mucosa to cigarette smoke, mechanical and chemical irritants. Nature 1983; 302: 251-253.

9. Collier JG, Fuller RW. Capsaicin inhalation in man and the effects of sodium cromoglycate. Br J Pharmacol 1984; 81: 113-117.

10. Midgren B, Hansson L, Karlsson J, Simonsson BG, Persson GA: Capsaicin-induced cough in humans. Am Rev Respir Dis 1992; 146: 347-351.

11. Fujimura M, Sakamoto S, Kamio Y, Matsuda T. Sex difference in the inhaled tartaric acid cough threshold in nonatopic healthy subjects. Thorax 1990; 45: 633-634.

12. Fujimura M, Kamio Y, Sakamoto S, Bando T, Myou S, Matsuda T. Tachyphylaxis to capsaicin-induced cough and its reversal by indomethacin in patients with the sinobronchial syndrome. Clin Autonom Res 1992; 2: 397401.

13. Fujimura M, Sakamoto S, Kamio Y, Matsuda T. Effects of methacholine-induced bronchoconstriction and procaterol-induced bronchodilation on cough receptor sensitivity to inhaled capsaicin and tartaric acid. Thorax 1992; 47: 441-445.

14. Ryan G. Standardization of inhalation provocation tests: Influence of nebulizer output, particle size, and method of inhalation. J Allergy Clin Immunol 1981; 67: 156-161.

15. Karlsson JA, Sant'Ambrogio G, Widdicombe J. Afferent neural pathways in cough and reflex bronchoconstriction. J Appl Physiol 1988; 65: 1007-1023.

16. Sant'Ambrogio JM. Information arising from the tracheobronchial tree of mammals. Physiol Rev 1982; 62: 531-569.

17. Widdicombe JG. Receptors in the trachea and bronchi of the cat. J Physiol 1954; 123: 71-104.

18. Hansson L, Wollmer P, Dahlback M, Karlsson J. Regional sensitivity of human airways to capsaicin-induced cough. Am Rev Respir Dis 1992; 145: 1191-1195.

19. Choudry NB, Fuller RW. Sensitivity of the cough reflex in patients with chronic cough. Eur Respir J 1992; 5: 298-300. 